\title{
OS DESAFIOS E AS INIQUIDADES DO ACESSO À SAÚDE BUCAL: UMA REVISÃO INTEGRATIVA DE LITERATURA
}

\author{
Ricardo Elias Duarte Rabelloㅜ; Ângela Xavier Monteiro \\ ${ }^{1}$ Mestrando em Saúde da Família, Universidade Estadual do Amazonas (UEA), Manaus, AM \\ ${ }^{2}$ Doutora em Saúde Coletiva, Universidade Estadual do Amazonas (UEA), Manaus, AM
}

DOI: 10.47094/IICNNESP.2021/49

\begin{abstract}
RESUMO
Quando falamos do acesso da população à Saúde Bucal, estamos à frente de um grande desafio, que envolve garantir um acesso de qualidade, facilitado, integral e resolutivo. O objetivo deste estudo foi analisar, através de uma revisão de literatura, a qualidade do acesso à saúde bucal e seus principais desafios, buscando levantar os fatores associados à inequidade e a falta de acesso a esse serviço. Para isso, foi realizada uma revisão integrativa utilizando a BVS com artigos dos últimos cinco anos. A estratégia de busca retornou 119 artigos, no entanto somente 17 foram incluídos. Foram identificados diversos fatores associados à falta de acesso como idade, escolaridade, baixa renda, dificuldade no acesso e limitação dos serviços ofertados. Para que hajam melhorias na Qualidade do Acesso, é necessário, portanto, uma reflexão sobre os serviços ofertados e sobre os possíveis fatores que possam favorecer ou dificultar o Acesso desses usuários à Saúde Bucal.
\end{abstract}

PALAVRAS-CHAVE: Acesso à Saúde Bucal. Equidade no Acesso aos Serviços de Saúde. Saúde Bucal.

AREA TEMÁTICA: Política e gestão em Saúde.

\section{INTRODUÇÃO}

A ampliação do acesso à população é um desafio da APS para a melhoria da qualidade da saúde. Garantir o acesso aos cuidados primários à saúde, em tempo oportuno, é um dos maiores desafios dos sistemas públicos de saúde, tanto no Brasil quanto em outros países (ROCHA et al.,2016). Uma APS forte e resolutiva depende de acesso facilitado, a fim de garantir o atendimento em tempo oportuno, no horário mais adequado, com agendamento confortável e onde o usuário seja atendido por sua equipe de referência (CURITIBA, 2014).

Quando falamos de acesso da população à Saúde Bucal na APS, também estamos à frente de um grande desafio, que envolve garantir um acesso de qualidade, facilitado, integral e resolutivo. Nesse ponto, embora tenha ocorrido uma oportuna ampliação do número de equipes de saúde bucal, o atributo de acesso esteja longe de ser considerado satisfatório. (CASOTTI et al., 2014). A formação odontológica ainda se baseia num modelo biologicista, curativo e organizado em espaços privados, de acesso individual e segmentado. Infelizmente estas características, que são típicas dos consultórios 
privados acabam refletindo nos serviços públicos de saúde, prejudicando a ampliação do acesso da população à Saúde Bucal (MARTELLI, 2010).

No que tange ao acesso à saúde bucal por regiões do Brasil, existem desigualdades regionais marcantes, como nas regiões Norte e Nordeste, que são regiões em pior situação se comparadas às demais regiões do país. Embora no Brasil se preconize a "universalidade" do acesso como um princípio do SUS, o acesso aos serviços de saúde bucal ainda é restrito nessas regiões. Além disto, desigualdades socioeconômicas se refletem na utilização de serviços de saúde bucal (BRASIL, 2012).

O objetivo deste estudo foi levantar e avaliar a qualidade do acesso à saúde bucal pela população no Brasil e de seus principais desafios por meio da revisão de literatura, buscando analisar os fatores associados à iniquidade e à falta de acesso a esses serviços, para suscitar uma discussão mais ampla sobre o tema em questão, e com isso propor mudanças e melhorias do acesso à população.

\section{METODOLOGIA}

Foi realizada uma revisão integrativa da literatura, com vistas a responder a seguinte questão: Como está o acesso da população à saúde bucal na atenção primária e qual a qualidade desse acesso? A busca foi realizada na base de dados Biblioteca Virtual da Saúde (BVS), com artigos publicados até 15/09/20, utilizando os seguintes critérios de inclusão: publicações em artigos dos últimos cinco anos; disponíveis em texto completo e nos idiomas português, inglês ou espanhol. Foram excluídos artigos publicados em outros idiomas, teses, dissertações e capítulos de livros e artigos que fugiam ao tema proposto.

$\mathrm{Na}$ busca utilizou-se o cruzamento dos descritores e operadores boleanos da seguinte forma: Acesso AND atenção primária AND Saúde Bucal e Acesso AND Saúde Bucal AND Serviços de Saúde Bucal. A partir da busca inicial, no total foram encontradas 119 publicações. Todas foram avaliadas primeiramente pelos títulos de forma independente, sendo selecionados 39 artigos, dos quais seis eram repetidos. Em um segundo momento, iniciou-se a leitura dos resumos dos 33 textos restantes, sendo excluídos aqueles que não responderam à questão norteadora do estudo, sendo obtido uma amostra de 17 artigos a serem lidos na íntegra para composição do trabalho.

\section{FUNDAMENTAÇÃO TEÓRICA}

Os dezessete artigos foram lidos na íntegra e observou-se que 12 desses artigos abordavam o tema a avaliação do acesso a serviços odontológicos, verificando a qualidade desse acesso sob a ótica da população e seus desafios. Nesses artigos, os autores identificaram a falta de acesso aos serviços odontológicos, onde encontraram associação desta com a idade, constatando que ocorre uma maior chance da falta de acesso a cada ano de idade incrementado, principalmente entre aqueles com menor renda per capita ou vulneráveis socialmente, demostrando a falta de equidade no acesso aos serviços de saúde odontológicos. Também nesses artigos foram apontados a relação entre a escolaridade e a dificuldade de acesso aos serviços de saúde bucal, onde analfabetos e indivíduos com até o ensino 
fundamental completo estiveram associados a menor probabilidade de ter acesso completo a esses serviços. A dificuldade no acesso aos serviços na APS e a própria limitação desses serviços ofertados, também foram apontados como fatores que contribuem para a falta de Acesso na Saúde Bucal, principalmente em crianças menores de 05 anos e nos idosos, o que fazem com que muitos usuários precisem procurar o setor privado para terem sua demandas atendidas.

Nos demais artigos, 02 abordaram o tema do impacto da qualidade do acesso à população, avaliando que existe grande impacto na qualidade de vida das pessoas onde havia falta de acesso aos serviços e aos cuidados de saúde bucal oferecidos pela APS. Um dos artigos tratou da avaliação da efetividade da implantação de uma agenda de atividades na melhoria do acesso aos serviços de saúde bucal e outros 02 artigos tratavam da compreensão da relação do profissional com o acesso, onde verificou-se falhas no processo de trabalho desses profissionais, sugerindo a educação permanente como forma de aprimorar esse processo.

Dos 17 artigos, 06 deles foram realizados pelos autores analisando municípios da região Sul, outros 06 da região Sudeste, 04 da região Nordeste e um analisando dados da PNAD 2013. Não foram encontrados estudos com municípios da Região Centro-Oeste e Região Norte, o que traz a discussão sobre a carência de estudos nessas regiões e a necessidade de levantamentos e investigações sobre a qualidade do acesso à saúde bucal também nessas regiões.

A análise dos estudos revelou diversos problemas que impactam na qualidade do acesso à Saúde Bucal da população, onde foram identificados diversos fatores associados à falta de acesso, como a renda e a idade, que causam iniquidades no acesso a esses serviços e impactam na qualidade de vida das pessoas. Falhas no processo de trabalho das equipes de Saúde, limitação de acesso aos serviços pela população, falta de estrutura e planejamento dos serviços nas unidades acabam colaborando negativamente nesse resultado. Podemos perceber que estamos diante de grandes desafios para a ampliação do acesso à saúde bucal para a população e que precisamos efetuar mudanças e melhorias para acabarmos com as inequidades hoje existentes.

Para concretizar tais mudanças é importante que os profissionais das equipes de Saúde Bucal, em conjunto com os demais profissionais das equipes da atenção primária, reflitam sobre o acesso da população aos serviços ofertados e sobre os possíveis fatores que possam facilitar ou dificultar a entrada dos usuários na unidade de saúde, utilizando a educação permanente como ferramenta que pode subsidiar este processo. Além disso, destaca-se a implantação de um fluxo de acesso ao cidadão, a partir de uma visão ampliada do cuidado, que envolva a análise e a definição das necessidades da população e do território, levando-a em consideração no planejamento das ações e serviços.

\section{CONSIDERAÇÕES FINAIS}

Os estudos selecionados mostram que o problema da falta de Acesso à Saúde Bucal ainda está presente em grande parcela da população, principalmente naquelas parcelas que mais necessitam de Acesso e dos cuidados de Saúde Bucal. A análise dos artigos permitiu identificar que os mais 
idosos e a população de baixa renda e escolaridade são os mais afetados, e que esses problemas estão relacionados à dificuldade e limitação no acesso, a problemas relacionados a organização do processo de trabalho das equipes, onde não se buscam melhorar a preparação dos profissionais em relação ao acesso em tempo oportuno, como por exemplo a utilização do Acesso Avançado, quando a demanda é equilibrada com a capacidade e não há demora, pois as consultas são suficientes para acomodar toda a demanda, inclusive a espontânea, e os relacionados à falta de estrutura, de cobertura e de planejamento dos serviços, o que acaba sobrecarregando as equipes, atrapalhando a eficiência do serviço e impactando na qualidade do acesso à população.

Podemos concluir que ainda há muitos desafios a serem transpostos para que consigamos ter realmente uma qualidade de acesso à saúde bucal satisfatória para a população, e que ainda existe iniquidade nesse acesso, o qual somente será resolvido quando esses obstáculos forem vencidos e mudanças no nosso processo de trabalho e no planejamento das ações forem implementadas.

\section{PRINCIPAIS REFERÊNCIAS}

BRASIL. Ministério da Saúde. Secretaria de Atenção à Saúde. Secretaria de Vigilância em Saúde. SB Brasil 2010: Pesquisa Nacional de Saúde Bucal: Resultados principais. Brasília, DF, 2012.

CASOTTI E. et al., Atenção em saúde bucal no Brasil: uma análise a partir da avaliação externa do PMAQ-AB. [S.I.]. Saúde Debate. 2014 Out;38(spe):140-57.

CURITIBA. Secretaria Municipal de Saúde de Curitiba. Saúde da Família. Novas possibilidades de organizar o acesso e a agenda na Atenção Primária à Saúde. Curitiba (PR): SUS; 2014.

MARTELLI, P. J. L. et al. Perfil do cirurgião-dentista inserido na Estratégia de saúde da Família em municípios do estado de Pernambuco, Brasil. Ciênc. Saúde Coletiva. Rio de Janeiro. 2010.

ROCHA S.A.; Bocchi S.C.M.; Godoy M.F. Acesso aos cuidados primários de saúde: revisão integrativa. [S.I.]. Physis. 2016 Mar; 26(1):87-111. 